\title{
A Triterpenoid Having Anticancer Activity Found in Stem Bark of Holoptelea integrifolia (Roxb.) Planch
}

\author{
Amir Hassan ${ }^{1^{*}}$, Munawwer Rasheed ${ }^{2},{\text { Mohsin } \text { Ali }^{3} \text {, Ghazala Ishrat }}^{4}$ and Mansoor Ahmed ${ }^{1}$ \\ ${ }^{1}$ Department of Pharmaceutical Chemistry, Faculty of Pharmacy, University of Karachi, Karachi, Pakistan \\ ${ }^{2}$ Centre of Excellence in Marine Biology and Department of Chemistry, University of Karachi, Karachi, Pakistan \\ ${ }^{3}$ Department of Chemistry, University of Karachi, Karachi, Pakistan \\ ${ }^{4}$ Department of Pharmaceutics, Barrett Hadgson University, Karachi, Pakistan
}

*Corresponding author: Amir Hassan, Department of Pharmaceutical Chemistry, Faculty of Pharmacy, University of Karachi, Karachi, Pakistan, Tel: +92 315 3632159; E-mail: ameerhassanhassan@yahoo.com

Received: August 17, 2018; Accepted: August 24, 2018; Published: September 07, 2018

Copyright: ( 2018 Hassan A, et al. This is an open-access article distributed under the terms of the Creative Commons Attribution License, which permits unrestricted use, distribution, and reproduction in any medium, provided the original author and source are credited.

\begin{abstract}
Studies on the chemical constituents of the stem bark of Holoptelea integrifolia (Roxb.) Planch have led to the isolation of a triterpenoid, oleanolic acid (1), the structure of the compound was elucidated via advanced spectroscopic techniques including EI (+), IR, ${ }^{1} \mathrm{H}-\mathrm{NMR}$ and ${ }^{13} \mathrm{C}-\mathrm{NMR}$. Oleanolic acid was isolated first time from the stem bark of $H$. integrifolia. Crude ethylacetate extract of the stem bark of $H$. integrifolia has been tested in vitro for its cytotoxicity by MTT assay. This paper is based on isolation and characterization of the chemical constituents.
\end{abstract}

Keywords: Holoptelea integrifolia (Roxb.) Planch; Stem bark; Materials and Methods Oleanolic acid

\section{Introduction}

Holoptelea integrifolia (Roxb) Planch (Ulmaceae) is a medicinal and ornamental plant which is widely distributed all over tropical and temperate regions of Northern Hemisphere including Pakistan, India, Nepal, Srilanka, Cambodia, Laos, Myanmar, Vietnam etc., [1]. Bark and leaf paste of the plant are used externally on the white patches or leukoderma [2]. It is also reported for the treatment of intestinal cancer [3]. The ethanol crude extracts of stem bark of $H$. integrifolia was found anti-oxidant which is comparable to the standard vitamin E [4]. Benzene, chloroform, methanol and aqueous extracts of stem bark of $H$. integrifolia showed anthelmintic activity against adult earth worm Pheretima posthuman [5]. Butanol, chloroform, hexane and ethylacetate extracts of stem bark of $H$. integrifolia were applied on six different cancer cell lines. Eethylacetate extract was found 3-fold more toxic in prostate cancer cell compare to HEK293 cell (standard) [6].

The stem bark contains the triterpenoidal-fatty acid esters, holptelin-A (epi-friedelinol palmitate) and holoptelin-B (epifriedelinol stearate), friedelin and epi-friedelinol, 2aminonaphthaquinone and $\beta$-sitosterol, $\beta$-D-glucose were also isolated from stem bark [7]. Fractionation of crude methanol extract of the stem bark of $H$. integrifolia lead to the isolation of lupeol, ellagic acid and $\beta$-sitosterol-D-glucoside [8]. Lupane series compounds, betulinic acid and betulin, were also reported in the ethanolic extract of bark of H. integrifolia [9].

Since cytotoxicity of ethyl acetate extract of stem bark on different cell lines have been evaluated in our previous study and it was found more toxic as compared to other extracts of the stem bark [6]. In our present study isolation and characterization of the ethyl acetate extract was carried out by Column Chromatography (CC), in order to identify the actual constituent, responsible for the cytotoxicity.

\section{Plant materials and chemicals}

The bark of the Holoptelea integrifolia plant was collected from the premises of the University of Karachi, Pakistan during January-April 2009 and identified by an expert of the University of Karachi. A herbarium voucher specimen No. 0045 was deposited in the museum of the Department of Pharmacognosy at University of Karachi, Pakistan. The purified chemicals used during the research work were commercially purchased from Oxoid (England) and Merck (Germany). All other reagents and solvents were purchased from VWR (West Chester, PA, USA) [6].

\section{Standardization}

Standardization of Holoptelea integrifolia (Roxb) Planch was performed using internationally acceptable assays and analysis [10] i.e., for pharmacognostic identification microscopic, macroscopic, sensory, and histological examinations were performed. Physiochemical examinations were determined by measuring extractive value, moisture contents and ash value. For microbiological examination total viable count (TVC) test was conducted. While, prephysiochemical examination were performed using wettest or dipped reagent and spectroscopic analysis [6].

\section{Fractionation and isolation}

Holoptelea integrifolia plant bark $(10 \mathrm{~kg})$ were cleaned and then chopped into small pieces. These pieces were percolated in $80 \%$ methanol at room temperature for 15 days. The percolate was filtered thrice separately by using Whatman filter paper No.1. Thereafter, under reduced pressure and controlled temperature $40^{\circ} \mathrm{C}$, the filtrate was evaporated to dryness and the methanolic extract was lyophilized to a powdered form. Lyophilized powder $(300 \mathrm{~g})$ was partitioned with an equal quantity of distilled water $(450 \mathrm{ml})$ and ethylacetate $(450 \mathrm{ml})$ 
Citation: Hassan A, Rasheed M, Ali M, Ishrat G, Ahmed M (2018) A Triterpenoid Having Anticancer Activity Found in Stem Bark of Holoptelea integrifolia (Roxb.) Planch. Nat Prod Chem Res 6: 340. doi:10.4172/2329-6836.1000340

Page 2 of 4

$1: 1$, ethylacetate layer was evaporated under reduced pressure and temperature $40^{\circ} \mathrm{C}$ to obtain ethylacetate extract [6]. The ethylacetate extract was triturated with warm $n$-hexane in order to obtain brown powder like n-hexane insoluble material (HIB-EA-HIS).

\section{Column chromatography}

Column Chromatography (CC) was performed on silica gel particle size $0.063-0.200 \mathrm{~mm}$ (70-230 mesh) ASTM (Merck, Germany) was used. Hexane insoluble (HIB-EA-HIS) fraction was subjected to Column Chromatography (CC), and 40 major fractions (1-40) were collected using the eluent (chloroform). Similar fractions were identified by TLC (solvent system chloroform) and pooled (10 and 11). Pooled fractions (10 and 11) were re-chromatographed with chloroform to get 1-40 fractions. Similar fractions (3-13) and (14-40) were pooled. Fraction (3-13) was re-chromatographed with chloroform to get 1-38 fractions. Similar fractions (1-20) were pooled and combined with previous left-over fractions (14-40) (isocratic) and subjected to CC with chloroform to get fractions (1-23). By TLC fractions (9-23) containing same compound were identified and pooled to get finally the isolated pure compound. It is important to mention that the GC-MS and EIMS analyses were performed from an outsource laboratory (H.E.J Research Institute of Chemistry, University of Karachi, Karachi, Pakistan) (Figure 1).

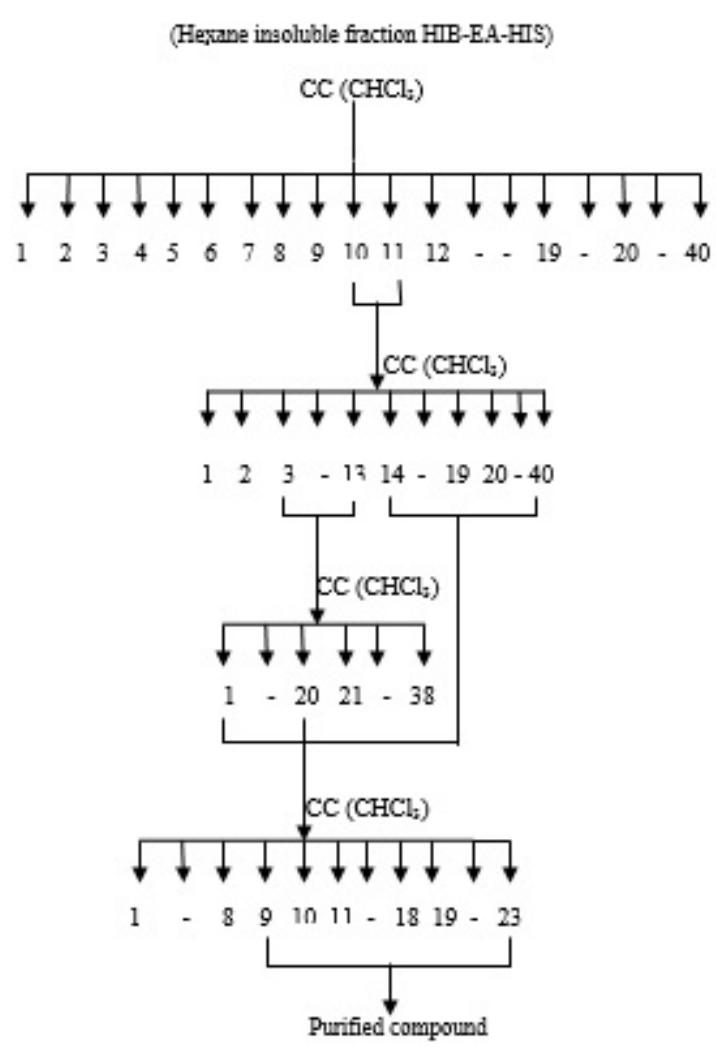

Figure 1: Column Chromatography (CC) of HIB-EA-HIS.

\section{Spectroscopy}

EIMS was performed on JEOL. The MS route JMS-600H, HREI-MS on Thermo Finnigan MAT 95 XP and FABMS (+ve/-ve) on JEOL JMS-
HX 110 mass spectrometers. Bruker Vector-22 Spectrophotometer was used to record IR data. The ${ }^{1} \mathrm{H}$ NMR experiments were recorded in $\mathrm{CDCl}_{3}$ on Bruker Avance 300, 400, 500, and 600 spectrometers working at 300,400,500, and $600 \mathrm{MHz}$, respectively. ${ }^{13} \mathrm{C} \mathrm{NMR}$ (BB and DEPT) were recorded at 75, 100, 125, and $150 \mathrm{MHz}$. Chemical shifts $(\delta)$ were calculated in ppm and coupling constant $(\mathrm{J})$ in Hertz $(\mathrm{Hz})$.

\section{Results}

Spectroscopic data of the pure compound obtained by column chromatography (cc) is summarized in the following Tables 1-4.

\section{El (+ mode) $(\mathrm{m} / \mathrm{z})$}

$\mathrm{m} / \mathrm{z}, 490.3(5 \%), 472.3$ (5), 456.4 (32), 438.3 (15), 423.3 (12), 410.3 (10), 395.3 (10), 377.3 (4), 349.393$), 316.2$ (6), 302.2 (8), 287.2 (4), 259.2 (8), 248.2(32), 234.1 (20), 219.1 (24), 207.1 (64), 189.1 (100), 175.1 (32), 161.1 (16), 147.1 (20),135.1 (45), 119.1 (34), 107.1 (28), 95.0 (32), 81.0 (34), 69.0 (26), 55.0 (28), $41(24)$.

Table 1: EI (+) data of the pure compound (1).

IR $\left(\mathrm{cm}^{-1}\right)$

3431.5, 2936.6, 2866.2, 1690.8, 1641.6, 1604.0,1456.6, 1382.0, 1234.7, 1105.8 1038.2, 884.9, 793.0,753.3, 599.1, 468.3 .

Table 2: IR data of the pure compound (1).

\section{${ }^{1} \mathrm{H}-\mathrm{NMR}(\boldsymbol{\delta})$}

$\delta 0.75,0.76,0.88,0.91,0,92,0.97,1.15,1.37,1.38,1.51,2.09,2.82,3.17,3.32$ $3.38,4.56,4.59,5.27$

Table 3: ${ }^{1} \mathrm{H}-\mathrm{NMR}$ data of the pure compound (1).

\begin{tabular}{|l|l|l|l|l|l|}
\hline $\begin{array}{l}\text { Carbon } \\
\text { position }\end{array}$ & $\begin{array}{l}{ }^{13} \mathbf{C} \text { shift } \\
(\mathbf{p p m})\end{array}$ & $\begin{array}{l}\text { Carbon } \\
\text { position }\end{array}$ & $\begin{array}{l}{ }^{13} \mathbf{C} \text { shift } \\
(\mathbf{p p m})\end{array}$ & $\begin{array}{l}\text { Carbon } \\
\text { position }\end{array}$ & $\begin{array}{l}{ }^{13} \mathbf{C} \text { shift } \\
(\mathbf{p p m})\end{array}$ \\
\hline 1 & 38.4 & 11 & 22.9 & 21 & 33.8 \\
\hline 2 & 27.2 & 12 & 123.3 & 22 & 32.4 \\
\hline 3 & 79.7 & 13 & 143.6 & 23 & 28.1 \\
\hline 4 & 40.0 & 14 & 42.2 & 24 & 15.5 \\
\hline 5 & 55.2 & 15 & 28.4 & 25 & 15.3 \\
\hline 6 & 18.2 & 16 & 24.1 & 26 & 17.7 \\
\hline 7 & 32.6 & 17 & 46.6 & 27 & 25.9 \\
\hline 8 & 40.2 & 18 & 41.9 & 28 & 182.3 \\
\hline 9 & 48.3 & 19 & 46.6 & 29 & 33.1 \\
\hline 10 & 37.8 & 20 & 30.4 & 30 & 24.2 \\
\hline
\end{tabular}

Table 4: ${ }^{13} \mathrm{C}-\mathrm{NMR}$ data of the pure compound (1).

\section{Discussion}

Mass spectrum (Table 1) of the pure compound (1) showed first largest fragment peak at $\mathrm{m} / \mathrm{z}$ 490. The molecular mass of 
saligcinnamide is 490 and its mass spectrum showed characteristic fragment ions peaks at $\mathrm{m} / \mathrm{z} 475,225,200,160,131$ and 72 due to presence of pregnane skeleton with $\mathrm{N}, \mathrm{N}$-dimethylaminoethyl and with $\mathrm{N}$-methyl, and N-3-phenylprop-2-en-1-one substituents at C-17 and $\mathrm{C}-3$, respectively [11]. When mass spectrum of saligcinnamide was compared with mass spectrum of (1) no any fragment ion was identical, therefore compound (1) was not found as saligcinnamide. Compound (1) gave second largest fragment peak at $\mathrm{m} / \mathrm{z} 472[\mathrm{M}$ (saligcinnamide) $\left.-\mathrm{H}_{2} \mathrm{O}\right]^{+}$or due to presence of hederagenin (molecular mass 472). Hederagenin showed characteristic fragment ions peaks at $\mathrm{m} / \mathrm{z} 471.3,405.2$, and 393.3 [12] which were not matched with the fragment ions of the compound (1). When third largest fragment peak of (1) at $\mathrm{m} / \mathrm{z} 456$ was taken as a molecular ion peak $[\mathrm{M}]^{+}$, it was found similar to the molecular ion peak of Betulinic acid, oleanolic acid, and ursolic acid with molecular formula $\mathrm{C}_{30} \mathrm{H}_{48} \mathrm{O}_{3}$. When mass spectrum of these compounds [13] were compared with the mass spectra of (1) they were almost found identical. The mass spectrum of compound (1) was found most likely to oleanoic acid because mass spectrum of oleanoic acid showed prominent peaks at $\mathrm{m} / \mathrm{z} 248\left[\mathrm{C}_{16} \mathrm{H}_{24} \mathrm{O}_{2}\right]^{+}$and $207\left[\mathrm{C}_{14} \mathrm{H}_{23} \mathrm{O}\right]^{+}$retro-Diels-Alder (RDA) fragments characteristic for $\Delta 12$-amyrine series with $\mathrm{COOH}$ group [14] $203\left[\mathrm{C}_{15} \mathrm{H}_{23}\right]^{+}$due to the loss of $\mathrm{COOH}$ from $\mathrm{m} / \mathrm{z} 248$ along with other fragments at $\mathrm{m} / \mathrm{z} 438$ $\left[\mathrm{M}-\mathrm{H}_{2} \mathrm{O}\right]^{+}, 410[\mathrm{M}-\mathrm{HCOOH}]^{+}, 392\left[410-\mathrm{H}_{2} \mathrm{O}\right]^{+}, 189\left[\mathrm{C}_{14} \mathrm{H}_{21}\right]^{+}$(base peak), $175\left[\mathrm{C}_{13} \mathrm{H}_{19}\right]^{+}, 133\left[\mathrm{C}_{10} \mathrm{H}_{13}\right]^{+}, 119\left[\mathrm{C}_{9} \mathrm{H}_{11}\right]^{+}$and $69\left[\mathrm{C}_{5} \mathrm{H}_{9}\right]^{+}$and these fragment ion peaks completely matched with the ion peaks of compound (1) [13].

IR spectrum (Table 2) showed a broad peak of hydroxyl group at $3431 \mathrm{~cm}^{-1}$, prominent carbonyl absorption at $1690 \mathrm{~cm}^{-1}$. These two peaks may likely be due to the presence of carboxylic acid functional group $(\mathrm{COOH})$. The peak at $2936 \mathrm{~cm}^{-1}$ may be due to the presence of $\mathrm{C}-\mathrm{H}$ stretch for alkanes. Double bonded peaks at $1641 \mathrm{~cm}^{-1}$ and 1604 $\mathrm{cm}^{-1}$. The peak at $1456 \mathrm{~cm}^{-1}$ may be due to the presence of $-\mathrm{CH}_{3}$ and $\mathrm{CH}_{2}$ - signals. The peak at $1382 \mathrm{~cm}^{-1}$ may be due to the presence of trisubstituted olefinic group, and C-O functionalities at 1234, 1105 and $1038 \mathrm{~cm}^{-1}$ [15].

${ }^{1} \mathrm{H}-\mathrm{NMR}$ spectrum (Table 3) of compound (1) showed seven tertiary methyl groups at $\delta 0.75,0.76,0.88,0.91,0,92,0.97$, and 1.15 on an oleanane skeleton. $\left(7 \mathrm{~s}, 21 \mathrm{H}\right.$, all $\left.-\mathrm{CH}_{3}\right), 1.37(\mathrm{~m}, 2 \mathrm{H}, \mathrm{H}-21), 1.38(\mathrm{~m}$, $2 \mathrm{H}, \mathrm{H}-16), 1.51$ (m, 5H, H-18, H-19 and H-15), 2.09 (m, 3H,H-1 and $\mathrm{H}-9$ ), 3.17 (t, $\left.{ }^{1} \mathrm{H}, \mathrm{J}=7 \mathrm{~Hz}, \mathrm{H}-2\right), 3.38$ (s, 2H, H-7), 4.56 (s, 2H, H-11), $4.59\left(\mathrm{~s},{ }^{1} \mathrm{H}, \mathrm{H}-12\right)$. A doublet doublet of one proton at $\delta 2.82$ and a triplet of one vinyl proton at $\delta 5.27$ were assigned to $\mathrm{H}-18$ and $\mathrm{H}-12$, respectively, suggesting an olea-12-ene skeleton. One methine proton at $\delta 3.23$ (dd, $\mathrm{J}=11.2$ and $4.4 \mathrm{~Hz}$ ) showed that (1) has at least one hydroxyl group [16].

The ${ }^{13} \mathrm{C}$ NMR (Table 4) consists of 30 carbons peaks. Eight quaternary, five tertiary, ten secondary and seven methyl carbon. The peak at $\delta 182.3$ may be due to the presence of carbonyl group. The two peaks at $\delta 123.3$ and $\delta 143.6$ may be due to the presence of a pair of sp2 hybridized carbons. The peaks at $\delta 28.4,15.5,15.3,17.7,25.92,33.1$ and 24.2 are likely due to methyl substituent. This is in agreement with the seven methyl $\left(\mathrm{CH}_{3}\right.$ positive) carbon atoms in (1). Compound (1) showed five methine $(\mathrm{CH})$ carbon atoms with signals at $\delta 79.7,55.2$, $48.3,123.3$, and 41.9 , respectively. Other signals were found similar to the ones reported for oleanolic acid [17]. All the above spectral data confirm that the compound (1) found to be as oleanolic acid (Figure 2).

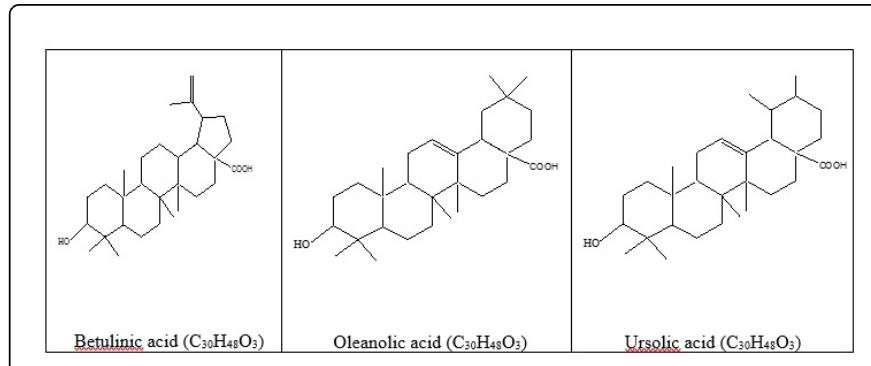

Figure 2: Structure of oleanolic acid in comparison with betulinic acid and Ursolic acid.

Oleanolic acid (OA) is a naturally occurring pentacyclic triterpenoid and possesses diverse pharmacological activities, including anti-cancer effects that have been confirmed in multiple types of human cancers. OA inhibited cell viability and proliferation and promoted cell apoptosis and G0/G1 phase cell cycle arrest in prostate cancer PC-3, DU145, and LNCaP cells, in a dose-dependent manner. In addition, OA was found to regulate the expression levels of apoptosis-related and cell cycle-related proteins, as well as the activity of PI3K/Akt pathway, in a dose-dependent manner. OA exerted anticancer effects in vitro in PC-3 and DU145 cells by repressing the PI3K/Akt pathway. In agreement, OA also suppressed the tumor growth of PC-3 cells in vivo via inhibition of the PI3K/Akt pathway. Anti-cancer properties of $\mathrm{OA}$ in prostate cancer cells, both in vitro and in vivo, have been demonstrated and provide the experimental evidence for the use of $\mathrm{OA}$ as an adjuvant agent for prostate cancer patients [18].

Oleanolic acid (OA) is widely distributed in dietary and medicinal plants and displays a selective cytotoxicity to cancer cells, primarily by inducing apoptosis and cell cycle arrest. It has been investigated that $\mathrm{OA}$ inhibited growth of tumor cells by affecting their metabolism. OA was found to activate AMP-activated protein kinase (AMPK), the master regulator of metabolism, in prostate cancer cell line PC-3 and breast cancer cell line MCF-7. AMPK activation is required for the antitumor activity of OA on cancer cells [19]. OA decreases the expression of the angiogenic vascular endothelial growth factor (VEGF) and decreased the development of melanoma-induced lung metastasis [20].

Oleanolic acid (OA), a plant-derived pentacyclic terpenoid, is known to have hepatoprotective effects. In has been found that OA induced autophagic cell death in multiple human gastric cancer cell lines. OA-induced autophagy was shown for the first time in human gastric cancer cells, evidenced by the formation of GFP-RFP-LC3 puncta and autophagosomes. OA suppressed phospho-mTOR through inhibition of the PI3 K/AKT and ERK/p38 MAPK signalling pathways and through activation of the AMPK signalling pathway [21]. Hepatocellular carcinoma (HCC) is an aggressive form of cancer, with high rates of morbidity and mortality, a poor prognosis and limited therapeutic options. The anticancer activity of OA in HepG2 human HCC cells has been demonstrated. Cell viability was evaluated using an MTT assay, following administration of various doses of oleanolic acid. The effect of OA on cell cycle phase distribution and mitochondrial membrane potential was evaluated using flow cytometry with propidium iodide and rhodamine-123 DNA-binding cationic fluorescent dyes. Fluorescence microscopy was employed to detect morphological changes in HepG2 cells following oleanolic acid 
treatment. The results revealed that OA induced a dose-dependent, as well as time-dependent inhibition in the growth of HepG2 cancer cells [22].

\section{Conclusion}

From insoluble n-hexane fraction of ethyl acetate extract of stem bark of $H$. integrifolia (HIB-EA-HIS) by column chromatography pure compound (1) as Oleanolic acid was isolated. Anticancer activity of oleanolic acid has been reported in the literature and its different mechanism of inhibition has been investigated in the last few years. Therefore, derivatization of the compound may lead to develop a novel anticancer drug.

\section{References}

1. Kirtikar K, Basu B (1999) Bishen Singh Mahendra Pal Singh Publication, Dehradun.

2. Harsha V, Hebbar S, Shripathi V, Hegde G (2003) Ethnomedicobotany of Uttara Kannada District in Karnataka, India-plants in treatment of skin diseases. Journal of Ethnopharmacology 84: 37-40.

3. Graham J, Quinn M, Fabricant D, Farnsworth N (2000) Plants used against cancer-an extension of the work of Jonathan Hartwell. Journal of Ethnopharmacology 73: 347-377.

4. Saraswathy A, Devi SN, Ramasamy D (2008) Antioxidant, heavy metals and elemental analysis of Holoptelea integrifolia Planch. Indian Journal of Pharmaceutical Sciences 70: 683.

5. Durga N, Padmaa MP (2010) Evaluation of anthelmintic activity of stem bark of Holoptelea integrifolia (Roxb) Planch. International Journal of Research in Ayurveda and Pharmacy 1: 637-641.

6. Guo H, Wang DS, Rizwani GH, Ahmed M, Hassan A, et al. (2013) Antineoplastic activity of Holoptelea integrifolia (Roxb.) Planch bark extracts (in vitro). Pakistan Journal of Pharmaceutical Sciences 26: 1151-1156.

7. Levekar G, Chandra K, Dhar B, Mangal A, Dabur R, et al. (2007) Database on Medicinal Plants Used in Ayurveda and Siddha. Central council for research in Ayurveda and Siddha 8: 522-531.

8. Durga N, Paarakh P (2012) Isolation of phytoconstituents from the stem bark of Holoptelea integrifolia (Roxb) Planch. Journal of Pharmacy Research 5: 532-533.

9. Ahmed M, Rizwani GH, Mohammed FV, Mahmood I, Ahmed VU, et al. (2013) Triterpenoid antioxidant agents found in Holoptelea integrifolia (Roxb) Planch. International Journal of Pharmaceutical, Chemical and Biological Sciences 3: 63-67.
10. Kumar D, Kumar K, Gupta J, Bishnoi N, Kumar S (2012) A mini review on chemistry and biology of Holoptelea integrifolia Roxb. Planch (Ulmaceae). Asian Pacific Journal of Tropical Biomedicine 2: 1200-1205.

11. Rahman A, Anjum S, Farooq A, Khan MR, Parveen Z, et al. (1998) Antibacterial steroidal alkaloids from Sarcococca saligna. Journal of Natural Products 61: 202-206.

12. Li HL, Qin ZM, Cai HD, Tan YF, Zhang XP, et al. (2015) Determination of $a$-hederin in rat plasma using liquid chromatography electrospray ionization tandem mass spectrometry (LC-ESI-MS/MS) and its application to a pharmacokinetic study. Analytical Methods 7: 2155-2161.

13. Ayatollahi AM, Ghanadian M, Afsharypour OM, Abdella M, Askari G (2011) Pentacyclic triterpenes in Euphorbia microsciadia with their T-cell proliferation activity. Iranian Journal of Pharmaceutical Research 10: 287.

14. Budzikiewicz H, Djerassi C, Williams DH (1964) Structure elucidation of natural products by mass spectrometry, Holden-Day San Francisco.

15. Onoja E, Ndukwe I (2013) Isolation of oleanolic acid from chloroform extract of Borreria stachydea. Jonural of Natural Products and Plant Resources 3: 57-60.

16. Hossain MA, Ismail Z (2013) Isolation and characterization of triterpenes from the leaves of Orthosiphon stamineus. Arabian Journal of Chemistry 6: 295-298.

17. Hung CY, Yen GC (2001) Extraction and identification of antioxidative components of Hsian-tsao (Mesona procumbens Hemsl.). LWT-Food Science and Technology 34: 306-311.

18. Li X, Song Y, Zhang P, Zhu H, Chen L, et al. (2016) Oleanolic acid inhibits cell survival and proliferation of prostate cancer cells in vitro and in vivo through the PI3K/Akt pathway. Tumor Biology 37: 7599-7613.

19. Liu J, Zheng L, Wu N, Ma L, Zhong J, et al. (2014) Oleanolic acid induces metabolic adaptation in cancer cells by activating the AMP-activated protein kinase pathway. Journal of Agricultural and Food Chemistry 62: 5528-5537.

20. Lúcio KA, Graça Rocha G, Monção-Ribeiro LC, Fernandes J, Takiya CM, et al. (2011) Oleanolic acid initiates apoptosis in non-small cell lung cancer cell lines and reduces metastasis of a B16F10 melanoma model in vivo. PloS One 6: e28596.

21. Nie H, Wang Y, Qin Y, Gong XG (2016) Oleanolic acid induces autophagic death in human gastric cancer cells in vitro and in vivo. Cell Biology International 40: 770-778.

22. Zhu YY, Huang HY, Wu YL (2015) Anticancer and apoptotic activities of oleanolic acid are mediated through cell cycle arrest and disruption of mitochondrial membrane potential in HepG2 human hepatocellular carcinoma cells. Molecular Medicine Reports 12: 5012-5018. 